\title{
SELECTED PROPERTIES OF EPOXY MORTARS WITH PERLITE AGGREGATE
}

\author{
Bernardeta Dębska', Lech Lichołai', Joanna Krasoń1 \\ 1 Department of Building Engineering, Rzeszow University of Technology, Poznańska 2, 35-959 Rzeszów, \\ Poland, e-mail: bdebska@prz.edu.pl, Lech.Licholai@prz.edu.pl, jkras@prz.edu.pl
}

Received: 2016.10 .15

Accepted: 2016.11.16

Published: 2017.01.01

\begin{abstract}
Contemporarily designed, new polymer concrete-like composites are increasingly often used in construction, particularly where high chemical resistance of the material is important. However, their widespread use is limited, mainly due to the cost of resin binders used. This is a significant problem, especially in a situation where it is necessary to obtain elements of a substantial volume. One solution to this inconvenience is to develop lighter concrete. The article presents a lightweight resin mortar obtained by substitution of sand with expanded perlite. Thanks to its properties, this aggregate allows for the production of a material with a more porous structure, which is highlighted by the received SEM photos. The binder in the mortars was epoxy resin, hardened with triethylenetetramine. The results of the tests carried out allow us to conclude that despite the significant reduction of strength parameters of mortar, we can obtain a material with lower weight, good chemical resistance and low water absorption, and characterized by significant thermal insulation. This type of composites can be used, among others, as cores in sandwich panels.
\end{abstract}

Keywords: polymer composite, epoxy mortars, perlite aggregate, mechanical properties, thermal conductivity, chemical resistance

\section{INTRODUCTION}

In recent years, the principles of sustainable development have been introduced in the construction industry [Czarnecki, 2013; Czarnecki and Justnes, 2012; Czarnecki et al., 2012]. According to this idea, we can observe that an increasing number of materials available on the market is dual- or multi-functional. This group of materials includes, among others, modified epoxy mortar, which combines the usage properties of at least two mortars with different characteristics and/or functions. They have good insulation parameters, while retaining the beneficial performance of resin mortars, including high mechanical strength and excellent chemical resistance [Lichołai and Dębska, 2014; Dębska and Lichołai, 2015; Dębska, 2015].

Epoxy mortars are a group of concrete-like polymer composites. However, these materials, unlike regular concrete, do not contain cement.
Its role is taken over by the synthetic resin, most often polyester, epoxy, or acrylic. The resin curing process occurs after the appropriate amount of hardener is added [Czarnecki, 2010; Reis and Jurumenha, 2013; Bediet et al., 2013]. The third major component of resin composites is filler. Its role is important because it typically makes up 75 to $80 \%$ by weight of the whole composition. Quartz sand is most often used to fulfil this function. However, mortars and concrete resins are also manufactured containing other types of aggregates, including lightweight aggregates.

Lightweight aggregates are a very important factor reducing the mass of the concrete, which is especially important in applications, such as high-rise constructions. In the case of resin composites, the application of light aggregates also allows the partial limitation of one of the main disadvantages of these materials, the high costs of production associated with the continuing high price of polymers. This is especially important in 
such applications, where it is necessary to obtain elements of a substantial volume.

Among the lightweight aggregates we can distinguish products of natural, eco-mineral origins, such as: wood, cork, rice husks and volcanically derived products. Artificial aggregates, expanded clay and shale are also applied (Novoa et al., 2004). In general, lightweight aggregates are obtained on the basis of blast furnace slag, fly ash or volcanic ash. However, the significant cost of obtaining this aggregate caused by the necessity of applying high combustion temperature, as well as the contraction and low resistance to cyclic freezing and thawing, has prompted many researchers to look for opportunities to improve these properties. A relatively new option that allows for a significant reduction in the weight of the produced items is to replace part of the sand with a mineral of volcanic origin called perlite. Perlite aggregate is a granular volcanic rock containing $2-5 \%$ water. Perlite mined from deposits in a form of rocks is initially ground up. In the final stage, expanded ground perlite rocks are obtained, which under the influence of temperatures of $+850^{\circ} \mathrm{C}$ up to $+1000^{\circ} \mathrm{C}$ increases in volume from five to twenty times. Water trapped inside the natural perlite structure turns to steam with a pressure exceeding the strength of the perlite, which causes it to crack. During this process, fractions from several $\mu \mathrm{m}$ to a few $\mathrm{mm}$ are formed. In parallel with the process of cracking, the sintering of volcanic glazes takes place, which is accompanied by a reduction of the glaze volume, due to which irregular spaces filled with air and steam are created, which then causes expansion of plastic glaze. The result of this process is a significant increase in volume (volumetric density decrease) in the product obtained [Liu et al., 2014; Pilatos et al., 2016].

The manufacture of cement-mortars with perlite is an issue that is known and used in the construction industry [Kramar and Bindiganavile, 2011]. The authors of publications describing cement-based composites containing perlite [Topçu and Işıkdağ, 2008; Gandagea et al., 2013; Sengula et al., 2011; Lanzón and García-Ruiz, 2008; Silva et al., 2010; Demirboğa and Gül, 2003] have primarily denoted the mechanical properties and thermal conductivity of this type of material. They have shown that the perlite reduces concrete and mortar strength parameters, although it is beneficial for thermal insulation of the obtained composites and significantly reduces their weight. M. Lanzón and P.A. García-Ruiz proved that a small addition of perlite (up to $7.08 \%$ of the mass of the entire composition) can improve the workability of the mixture. The work of these authors also presents interesting results of studies on the chemical resistance of plasters that contain perlite, supported by photographs made by using scanning electron microscopy.

Little information can be found in the literature concerning the application of perlite in resin mortars. A team under the direction of P. Łukowski attempted modification of polyester mortars with waste perlite dust, which served the role of microfiller in this composition. (Lukowski et al., 2014a, 2014b). Perlite dust changes the technology characteristics of the mixture, affecting - among others - the time of gelation and bonding of the resin binder. At the same time, the authors showed the lack of any significant impact of this component on the strength characteristics of the mortar obtained. It was also found that the chemical resistance of these composites was very good.

The analysis of the literature leads to the conclusion that partial substitution of sand with perlite may be an interesting way of modification of epoxy mortar. The results of the study presented in this article confirm that such an approach allows to obtain a new mortar with a reduced mass of material, and good physico-mechanical properties at the same time. Increasing the volume share of perlite in place of the sand causes reductions in strength parameters; however, in return, a number of other features improve, including thermo-isolation, adhesion, resistance to capillary action and the degree of noise reduction. The irregular, slightly porous surface of perlite allows the creation of very good mixtures with resin, which can be used in the manufacture of paints and plasters, roofing parts, bathroom fittings and installations, sandwich panels, artificial marble and putties, sealants and adhesives used in construction chemistry.

\section{EXPERIMENTAL PROTOCOLS}

\section{Materials}

Epidian 5 epoxy resin was used to obtain resin mortars. Z-1 hardener (triethylenetetramine) the amount of which was $10 \%$ (by weight) compared to the amount of resin, was used to cure the resin. The selected properties of the resin and the hardener are shown in tables 1 and 2, respectively. 
Table 1. Selected parameters characterizing Epidian 5 epoxy resin

\begin{tabular}{|c|c|c|c|c|}
\hline Resin type & Density $\left[\mathrm{g} / \mathrm{cm}^{3}\right]$ & Viscosity $25^{\circ} \mathrm{C}[\mathrm{mPa} \mathrm{s}]$ & Molecular mass $[\mathrm{g} / \mathrm{mole}]$ & Epoxide number LE [mole/100g] \\
\hline Epidian 5 & 1.17 & 30000 & 450 & 0.49 \\
\hline
\end{tabular}

Table 2. Selected physiochemical properties of Z-1 hardener

\begin{tabular}{|c|c|c|c|c|c|}
\hline Kind of hardener & Density $\left[\mathrm{g} / \mathrm{cm}^{3}\right]$ & $\mathrm{pH}$ & $\begin{array}{c}\text { Boiling temperature } \\
{\left[{ }^{\circ} \mathrm{C}\right]}\end{array}$ & Form & Water solubility \\
\hline Z-1 & 0.981 & 12 & 277 & light yellow liquid & soluble \\
\hline
\end{tabular}

The aggregate was quartz sand of a $0-2 \mathrm{~mm}$ grain size in accordance with the PN-EN 196-1 specification. Modification of the mortar consisted in the substitution of sand with expanded perlite with a volumetric density equal to $0.18 \mathrm{~g} / \mathrm{cm}^{3}$. Grain-size curves for sand and perlite used in the study are shown in Figure 1. Determination of the composition of the grain size was carried out in accordance with the PN-EN 933-1:2000 standard.

On the basis of the available literature data and our own results of a preliminary study on resin mortar, a mass ratio of resin to aggregates at the level of 0.25 was established.

Table 3. Mix proportions of mortar formulations

\begin{tabular}{|c|c|c|c|}
\hline \multirow{2}{*}{\multicolumn{2}{|c|}{ Test series }} & Resin : sand & Perlite : sand \\
\hline & & $(\mathrm{m} / \mathrm{m})$ & $(w / w)$ \\
\hline \multirow{7}{*}{$\mathrm{P}$} & $P-0$ & \multirow{7}{*}{$20: 80$} & $0: 100$ \\
\hline & $P-10$ & & $10: 90$ \\
\hline & $P-15$ & & $15: 85$ \\
\hline & $P-30$ & & $30: 70$ \\
\hline & $P-50$ & & $50: 50$ \\
\hline & $P-70$ & & $70: 30$ \\
\hline & $P-100$ & & $100: 0$ \\
\hline
\end{tabular}

\section{METHODS}

\section{Sample preparation}

An appropriate amount of epoxy resin was weighed out and mixed thoroughly with the curing agent, forming $10 \%$ by weight of the resin weight, until a homogeneous structure was obtained. The prepared resin composition was placed into a laboratory mixer bowl and stirred with normalized sand, which was earlier weighed out and mixed with an appropriate amount of perlite, while at the same time maintaining mixing time and a constant speed of the mixers. The prepared mortar was placed in steel moulds of 40x40x160mm for endurance tests. For each composition, samples of $60 \times 60 \times 5 \mathrm{~mm}$ were also prepared to study the absorption and chemical resistance, and samples of $300 \times 300 \times 20 \mathrm{~mm}$, for testing the thermal conductivity factor. In order to ensure that the process of curing takes place, the samples were left for 7 days under laboratory conditions. Depending on the amount of the added perlite, the samples varied in colour, as shown in Figure 2.

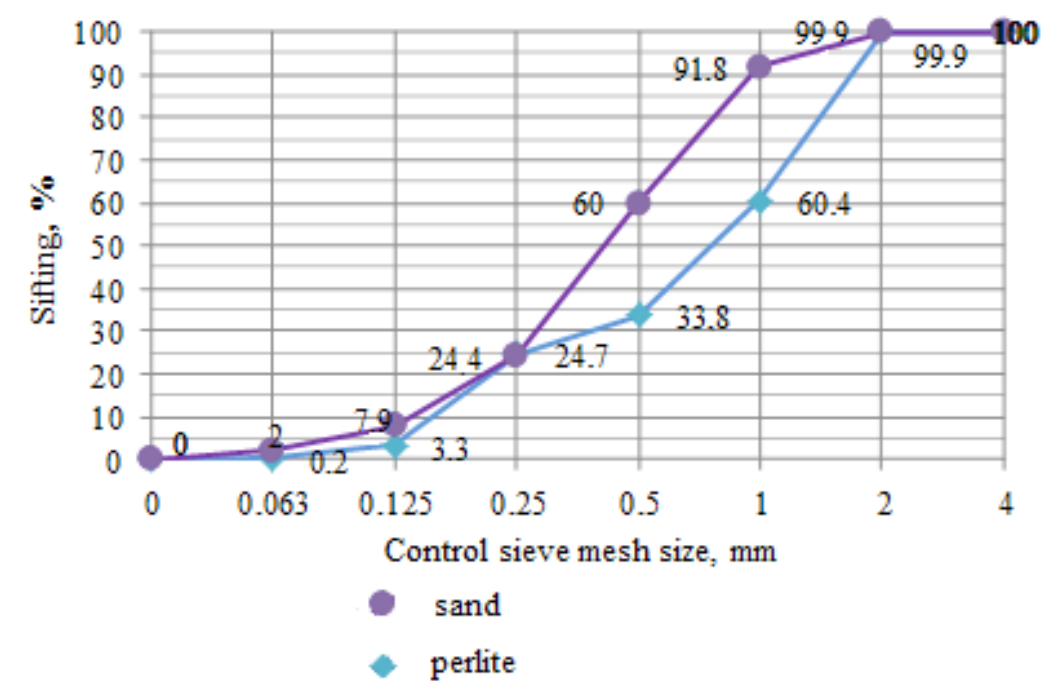

Figure 1. Grain-size curves for perlite and sand used for testing 


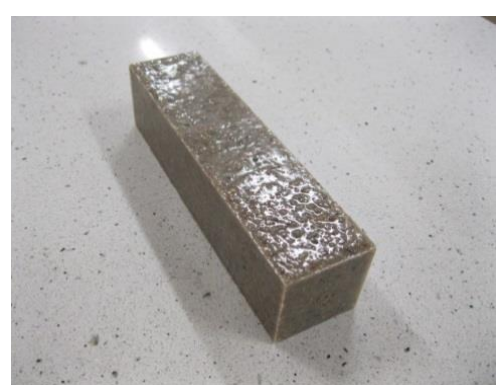

(A)

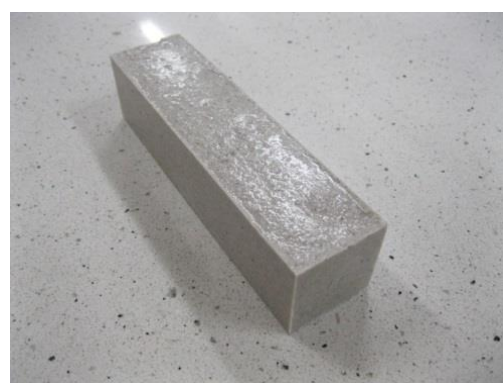

(B)

Figure 2. Samples of 10\% perlite content (A) and 100\% perlite (B)

\section{TEST METHODS}

\section{Bending and compressive strength}

Bending strength and compressive strength tests were carried out on endurance machines with appropriate inserts (Fig. 3), in accordance with the PN-EN 196-1:2006 standard. For testing the compressive strength two halves were created from the trabeculae after the bending strength test.

Percentage change in weight after immersion in aqueous solution

Determination of the weight changes of mortar samples subjected to exposure to water and corrosive solutions was performed according to PN-EN ISO 175:2002 standard. The test uses the following aggressive media: $10 \%$ sulphuric acid solution, $10 \%$ solution of sodium hydroxide and a $10 \%$ solution of sodium chloride. In addition, an assessment of the macroscopical colour and appearance of the surface of the samples was carried out. After drying the samples at a temperature of $50 \pm 2^{\circ} \mathrm{C}$ and establishment of a constant weight they were weighed and then placed in a container with water at a temperature of $23 \pm 2{ }^{\circ} \mathrm{C}$ (Fig. 5). The percentage change in weight was determined by immersion of samples and weighing them for another seven days, and then after 14 days.

For each sample, the change in weight (c) was calculated on the basis of the following formula:

$$
c=\frac{m_{2}-m_{1}}{m_{1}} \times 100 \%
$$

where: $m_{1}-$ is the weight of the sample, expressed in milligrams $(\mathrm{mg})$, after initial drying, before immersion in water,

$m_{2}-$ is the weight of the sample, expressed in milligrams (mg), after a given duration of immersion in water.

The end result was designated as the arithmetic mean of the three values obtained for the three samples tested at the end of this same duration of immersion.

\section{Volume density}

Determination of volume density was conducted according to PN-85/B-04500:1985 standard, for samples with dimensions of $40 \times 40 \times 160$ $\mathrm{mm}$. The weight of the trabeculae was marked on the technical scales. The volume of the samples was calculated on the basis of their dimensions.

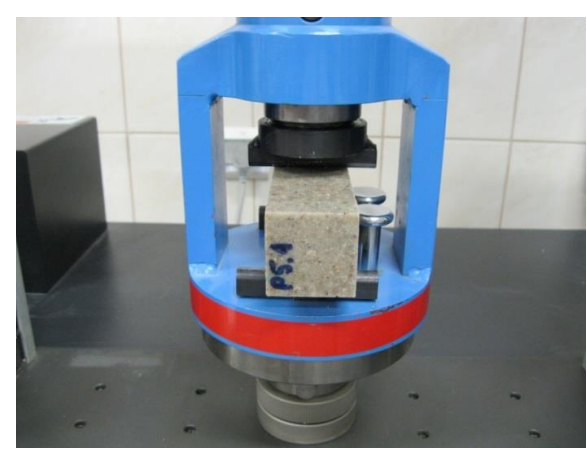

(A)

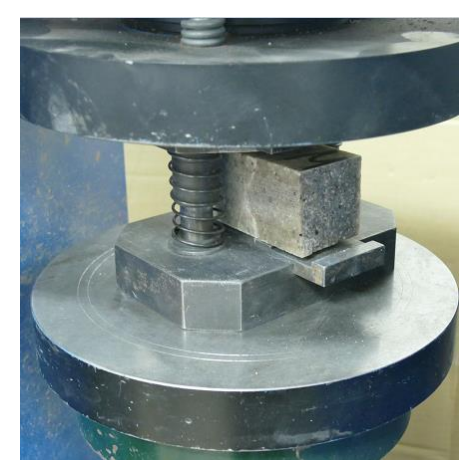

(B)

Figure 3. Insert to test bending (A) and compressive (B) strengths 
The volume density value was set in $\mathrm{g} / \mathrm{cm}^{3}$ according to the formula (2):

$$
\rho=m / V
$$

where: $\rho$ - is the volume density, $\mathrm{g} / \mathrm{cm}^{3}$, $m$ - is the mass of the test sample, $g$, $V$ - is the volume of the sample, $\mathrm{cm}^{3}$.

\section{Thermal conductivity $\lambda$}

Determination of the thermal conductivity coefficient were carried out on samples with dimensions of $300 \times 300 \times 20 \mathrm{~mm}$ using the plate method.

\section{RESULTS AND DISCUSSION}

\section{Bending and compressive strength}

The average values of the bending and compressive strength of epoxy mortars, depending on the contents of the perlite in the composites is shown in table 4 together with the calculated standard deviation.

Table 4. The results of tests of bending and compressive strength of samples of epoxy mortars along with standard deviation

\begin{tabular}{|c|c|c|}
\hline $\begin{array}{c}\text { Perlite } \\
\text { content, } \\
\%\end{array}$ & $\begin{array}{c}\text { Bending strength } \\
\bar{f}_{f \pm} \sigma_{\bar{x}}\end{array}$ & $\begin{array}{c}\text { Compressive strength } \\
\bar{f}_{c \pm} \sigma_{\bar{x}}\end{array}$ \\
\hline 0 & $21.83 \pm 0.26$ & $97.00 \pm 1.22$ \\
\hline 10 & $21.76 \pm 1.13$ & $89.63 \pm 211$ \\
\hline 15 & $21.66 \pm 0.76$ & $85.08 \pm 0.76$ \\
\hline 30 & $17.16 \pm 1.22$ & $59.62 \pm 2.54$ \\
\hline 50 & $17.04 \pm 1.23$ & $52.88 \pm 2.35$ \\
\hline 70 & $13.84 \pm 0.89$ & $51.45 \pm 1.62$ \\
\hline 100 & $10.98 \pm 0.87$ & $51.90 \pm 2.68$ \\
\hline
\end{tabular}

On the basis of the results of strength tests, it can be concluded that with an increase in perlite content of composites the strength properties deteriorate. However, at $10 \%$ substitution of sand, perlite managed to achieve results comparable to those that characterize unmodified mortar (bending strength of $21.8 \mathrm{MPa}$, compressive strength of $89.6 \mathrm{MPa}$ ). An increase in the content of epoxy mortar modifier to the level of $15 \%$ by weight causes a slight deterioration of the mechanical characteristics. Further substitution significantly lowers the value of strength parameters, which is particularly visible in the case of bending strength. Complete replacement of sand with expanded perlite caused a drop in the value of this feature by almost $50 \%$. However, despite this, bending strength is still higher than the $7.2 \mathrm{MPa}$, i.e. the value that characterises cement mortar. Differences in compressive strength associated with the percentage related to the replacement of sand with perlite in the range $30-100 \% \mathrm{w} / \mathrm{w}$ are small, $7.72 \mathrm{MPa}$ at most. Compressive strength values which fall within the range of 59.62 MPa to 51.90 $\mathrm{MPa}$ are close to the upper limit of the strength assigned to ordinary cement concrete of $60.0 \mathrm{MPa}$.

\section{Volume density}

Figure 4 presents the impact of perlite on the volume density of epoxy mortar. With increasing amounts of the added modifier, the volume density decreased. The largest decrease in the density was noted for mortar in which $100 \% \mathrm{w} / \mathrm{w}$ of the sand had been replaced with perlite. In that case, the density amounted to $48.4 \%$ of the volume density of the unmodified mortars. However, it was found that for all modified mortars the density of the composite was less than in the case of cement mortar.

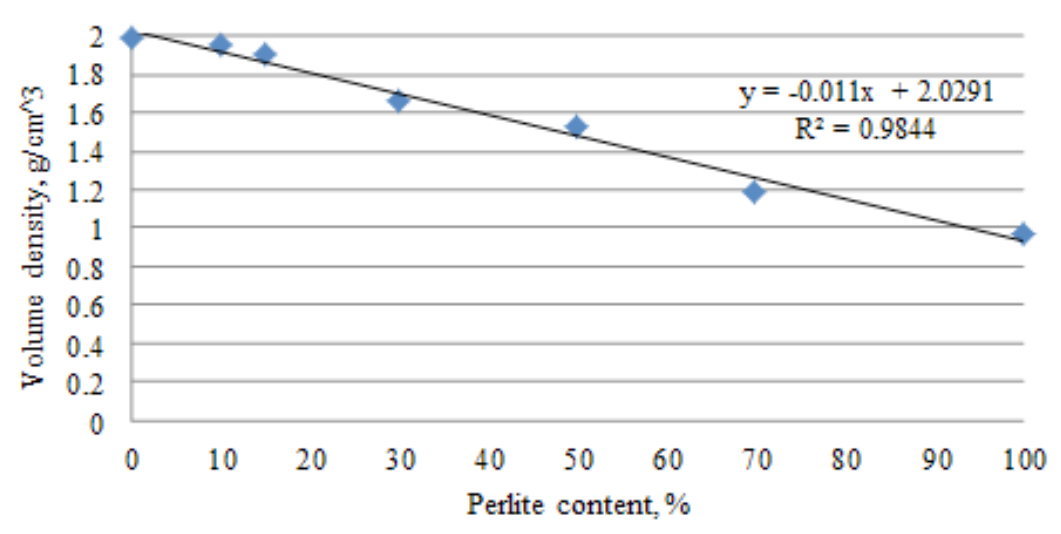

Figure 4. The effects of perlite on volume density of epoxy mortar 


\section{Results of tests of microstructure}

In order to specify the microstructure, photographs were taken of sections of samples of polymer mortar using a differential scanning microscopic at $250 \times$ magnification. Figure 5 shows photographs of sections of selected samples of mortar.

While analysing the presented photographs of epoxy mortars, we can notice the distinct perlite particles, forming a tight porous structure and grains of sand of various granulations, combined in a continuous phase of polymer matrix. There are also small amounts of air bubbles. Observation of the section allows to draw a conclusion that the composition in which the perlite replaced the sand completely has a much more porous structure (Fig. 5B), which is reflected in the physico-mechanical parameters obtained in the tested mortar.

\section{Water absorption}

The next parameter to be monitored was water absorption. Testing was done to determine the effect of the perlite additive to epoxy mortars on their absorption of water. The results are shown in Figure 6.

Absorption increased with increasing amounts of added modifier and the duration of exposure. Differences in the changes of this parameter for unmodified samples and those containing perlite are considerable and this is already observed from the first day of immersion in water. The lowest water absorption throughout the period of study was of mortar without modifier $(0.14 \%-0.30 \%)$. During the initial four days, the absorption reached the largest increase. For mortar without a modifier - this increase amounted to $82.7 \%$, with $10 \%$ content of perlite $-93.4 \%$, with $15 \%$ perlite -151.5 percent. In the case when only perlite was used as an aggregate, the gain from absorption was as high as $314.8 \%$. In consecutive days there are variations in the absorption, the greatest for perlite content of $10 \%$. We can conclude that even a small amount of perlite already causes an increase in water absorption. Replacing quartz sand as a filler, mortar with perlite leads to an increase in porosity of the composite, and this substantially affects the increase in its

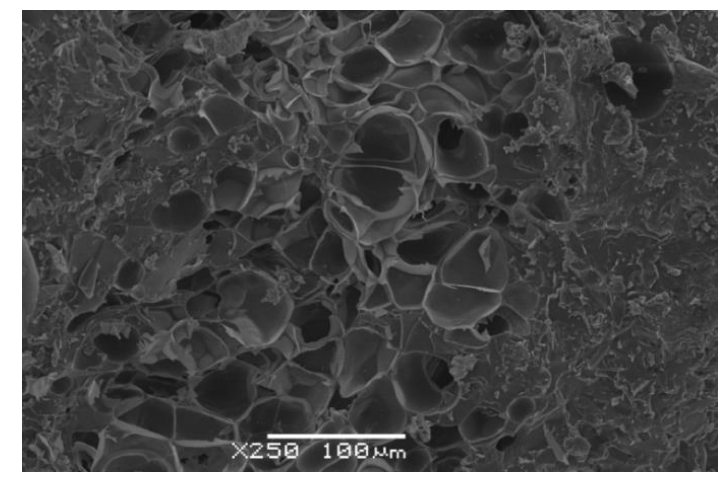

(B)

Figure 5. Photo-micrographs from SEM of mortar based on epoxy resin Epidian 5 with the addition of modifier, (A) $-10 \%$ perlite, (B) $-100 \%$ perlite

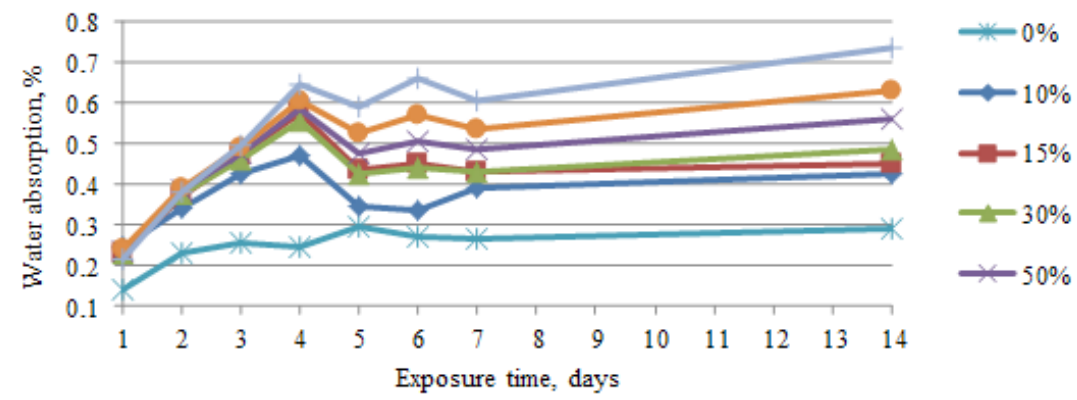

Figure 6. The dependency of water absorption of polymer mortars on the percentage of perlite and the duration of the immersion 
absorbency. During this test, the impact of water on the colour and appearance of the surface of the samples was also observed. A light tarnishing was noted in mortar samples after immersion in water. The samples of $100 \%$ perlite content were an exception, as they did not change colour.

\section{Chemical resistance}

In a similar way tests were also carried out on changes in the resistance of mortar to the action of selected aggressive media. The results of the monitoring of changes in these parameters are presented in Figures 7-9.

A general trend is observed for increased weight changes with increasing degree of substitution of sand with perlite and the duration of exposure. However, with contents of perlite up to $15 \% \mathrm{w} / \mathrm{w}$, these changes are significantly lower compared to the weight changes of samples con- taining higher amounts of modifier and even after a 14-day exposure in each of the solutions they do not exceed the value of $0.75 \%$. For samples of mortar with perlite content of $30 \% \mathrm{w} / \mathrm{w}$ and greater, there was a significant decrease in the weight of samples; however, in the case of all the aggressive media these do not exceed the value of $4.2 \%$. Therefore, these are lower than the mass variation (equal to $32 \%$ ) determined for cement mortars described in the literature (Reis, 2010). Account should be taken of the fact that the samples have undergone extreme exposure in the laboratory (total immersion), and in natural conditions the exposure is more limited. Observation of changes in the appearance of the samples during the exposure helped to draw the following conclusions: - The samples immersed in a solution of sulphuric acid were lightly matted, compared to samples before immersion.

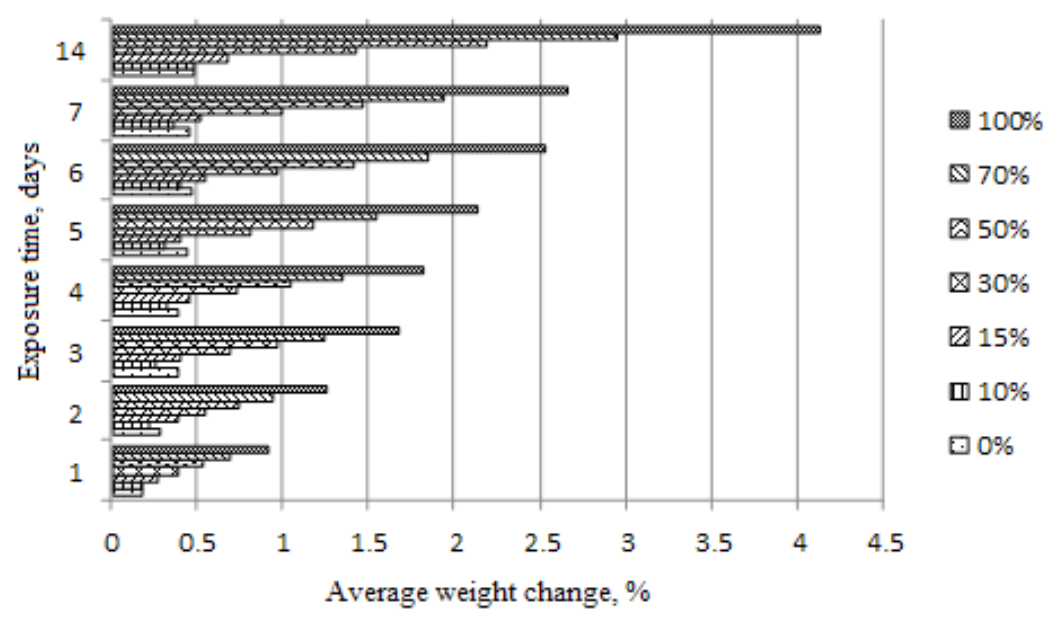

Fig. 7. The relationship of polymer mortar weight changes to the percentage of perlite and the duration of immersion in a $10 \%$ solution of sulphuric acid

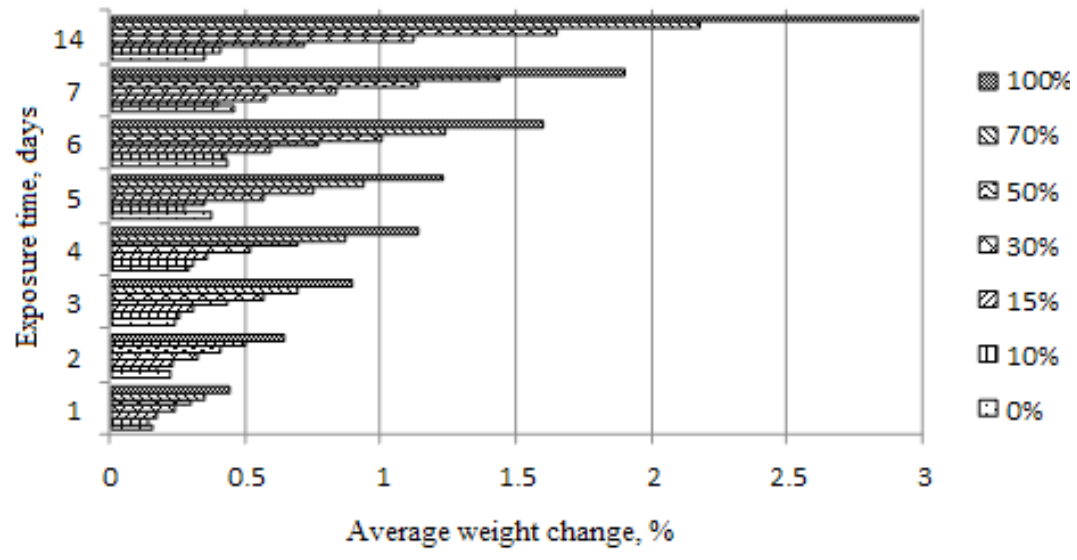

Fig. 8. The relationship of polymer mortar weight changes to the percentage of perlite and the duration of immersion in a $10 \%$ solution of sodium hydroxide solution 


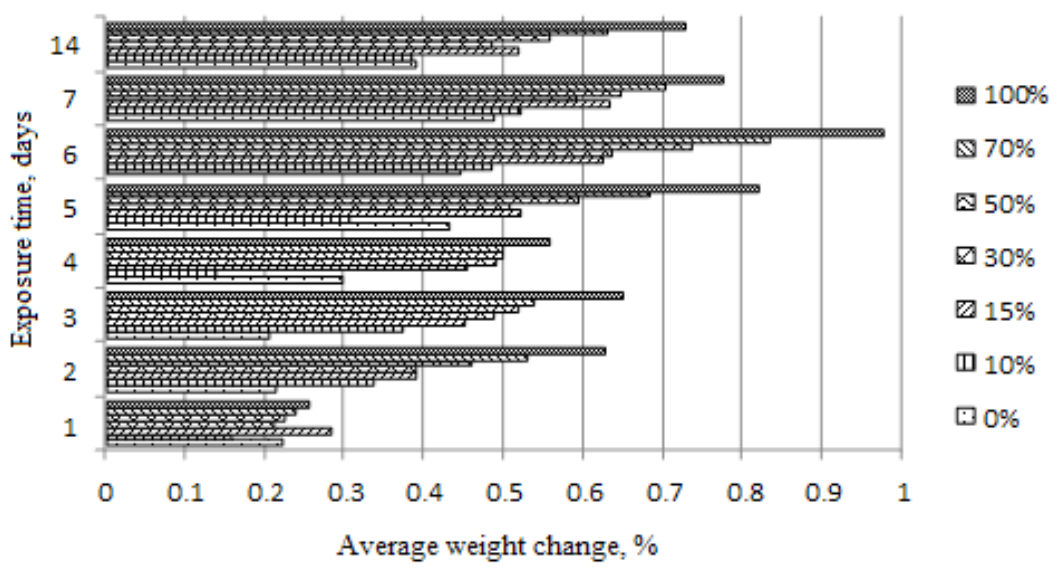

Fig. 9. The relationship of polymer mortar weight changes to the percentage of perlite and the duration of immersion in a $10 \%$ solution of sodium chloride

- The samples immersed in a solution of sodium hydroxide were also slightly matted in relation to the samples before immersion.

- Samples exposed to a solution of sodium chloride were lightly matted, compared to samples before immersion.

- No change was observed in the colours of the samples in the case of samples containing perlite $100 \% \mathrm{w} / \mathrm{w}$. This conclusion applies to all of the solutions.

\section{Coefficient of thermal conductivity}

Figure 10 shows the effect of perlite on the coefficient of thermal conductivity $\lambda$. Just a small addition of perlite caused a significant reduction of this parameter by almost $50 \%$. With the increase of perlite content in the mortar, the coefficient of thermal conductivity decreases. These changes can be described by a logarithmic dependency, with a high coefficient of determination at the level of 0.9714 .

\section{CONCLUSIONS}

On the basis of the obtained results concerning the monitoring of the changes in selected epoxy mortar properties, the following conclusions can be drawn:

1. A small addition of perlite $(0-15 \% \mathrm{w} / \mathrm{w}) \mathrm{did}$ not significantly affect the bending strength of epoxy mortar. These strength values lie between 21.66-21.83 MPa. In the case of compressive strength, the differences are larger (85.08-97.0 MPa), but they do not cause restrictions in the use of the mortar in the construction industry. A small amount of the modifier leads to more accurate filling of the gaps between the grains of sand with perlite and despite partial exchange of silicate aggregate with light aggregate, the drop in strength is small.

2. Complete replacement of sand with expanded perlite significantly worsens the mechanical properties. The strength values of mortar con-

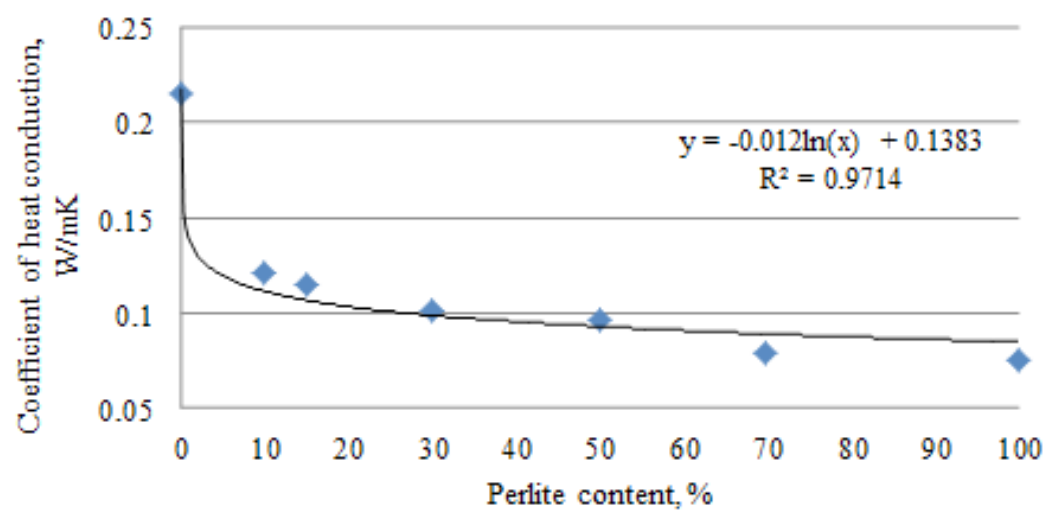

Fig. 10. The impact of perlite on thermal conductivity $\lambda$ 
taining $100 \% \mathrm{w} / \mathrm{w}$ perlite for the bending and compressive strength were respectively $64.9 \%$ and $47.5 \%$ of the strength of mortar based solely on sand.

3. Applying solely perlite as an aggregate significantly reduces the weight of the mortar: its volume density is $48.4 \%$ of the density of mortar containing only sand. This is essential in order to apply the mortar to, for example, use in inter-storey resin floors or ceilings.

4. It can be seen that a small addition of perlite already causes a significant increase in water absorption. Replacing quartz sand as mortar filler with perlite leads to an increase in porosity of the composite, which takes place at the expense of increasing its absorbency. Due to the use of sealed epoxy resin as a binder, samples were characterised by much lower water absorption than traditional cement-based mortars.

5. From the results of the chemical resistance test, it can be concluded that in the event of a total replacement of sand with expanded perlite, the biggest weight gains are observed for the $10 \%$ solution of sulphuric acid and this parameter reaches a maximum of about $4.0 \%$. Meanwhile, the smallest weight changes occur in the case of the samples immersed in a solution of sodium chloride, where the maximum weight gain does not exceed $1.0 \%$.

6. No significant change was observed in the appearance and colour of samples subjected to the action of aggressive media.

7. In the course of preparing samples with increased contents of perlite, an improvement in the workability of the mortar could be observed.

8. With just $10 \% \mathrm{w} / \mathrm{w}$ substitution of sand with perlite, composites with very good thermal insulation can be obtained. Thermal conductivity in this case was improved by nearly $50 \%$ in relation to the epoxy mortars obtained exclusively on the basis of quartz sand.

9. The findings confirm the conclusion that with substitution by sand of up to $15 \% \mathrm{w} / \mathrm{w}$, composites with high mechanical strength, excellent chemical resistance and low water absorption and thermo-isolation can be obtained. This type of composites can be used as, among others, cores of sandwich panels, prefabricated components or resin flooring.

\section{REFERENCES}

1. Bedi, R., Chandra, R., and Singh, S.P. 2013. Mechanical Properties of Polymer Concrete. Hindawi Publishing Corporation. Journal of Composites, 1.

2. Czarnecki, L. 2010. Polymer concretes. Cem Lime Concr. 2, 63.

3. Czarnecki, L. 2013. Sustainable Concrete; Is Nanotechnology the Future of Concrete Polymer Composites. Advanced Materials Research, 687, Ed. Ru Wang and Zhenghong Yang, Trans Tech Publications Ltd, 3.

4. Czarnecki, L., and Justnes, H. 2012. Sustainable and Durable Concrete. Cement Lime Concrete, 6,341 .

5. Czarnecki, L., Kaproń, M., Piasecki, M., and Wall, S. 2012. Budownictwo zrównoważone budownictwem przyszłości. Inżynieria i Budownictwo, 1, 18.

6. Dębska, B. 2015. Modification of Polymer Composites by Polyethylene Terephthalate Waste. In P.M. Visakh and M. Liang, Eds., Poly(ethylene Terephthalate) Based Blends, Composites and Nanocomposites. Elsevier, Inc., pp. 195.

7. Dębska, B., and Lichołai, L. 2015. The selected mechanical properties of epoxy mortar containing PET waste. Construction and Building Materials, 94, 579.

8. Demirboğa, R. and Gül, R. 2003. Thermal conductivity and compressive strength of expanded perlite aggregate concrete with mineral admixtures. Energy and Buildings, 35, 1155.

9. Gandagea, A.S., Vinayaka Raob, V.R., Sivakumarc, M.V.N., Vasanb, A., Venud, M., and Yaswanthe, A.B. 2013. Effect of Perlite on Thermal Conductivity of Self Compacting Concrete. Procedia - Social and Behavioral Sciences, 104, 188.

10. Kramar, D., and Bindiganavile, V. 2011. Mechanical properties and size effects in lightweight mortars containing expanded perlite aggregate. Materials and Structures, 44, 735.

11. Lanzón, M., and García-Ruiz, P.A. 2008. Lightweight cement mortars: Advantages and inconveniences of expanded perlite and its influence on fresh and hardened state and durability. Construction and Building Materials, 22, 1798.

12. Lichołai, L., and Dębska, B. 2014. A study of the effect of corrosive solutions on selected physical properties of modified epoxy mortars. Construction and Building Materials, 65, 604.

13. Liu, W.V., Apel, D.B., and Bindiganavile, V.S. 2014. Thermal properties of lightweight dry-mix shotcrete containing expanded perlite aggregate. Cement \& Concrete Composites, 53, 44.

14. Łukowski, P., Sokołowska, J.J., and Kępniak, M. 2014a. Wstępna ocena możliwości zastosowania 
odpadowego pyłu perlitowego w budowlanych kompozytach polimerowych. Budownictwo i Architektura, 13, 119.

15. Łukowski, P., Sokołowska, J.J., Adamczewski, G., and Smarż-Kępniak, M. 2014b. Odporność chemiczna kompozytów polimerowych zawierających odpadowy pył perlitowy. Przegląd Budowlany, 5,46 .

16. Novoa, P.J.R.O., Ribeiro, M.C.S., Ferreira, A.J.M., and Marques, A.T. 2004. Mechanical characterization of lightweight polymer mortar modified with cork granulates. Composites Science and Technology, 64, 2197.

17. Pilatos, G., Samouhos, M., Angelopoulos, P., Taxiarchou, M., Veziri, Ch., Hutcheon, R., Tsakiridis, P. and Kontos, A.G. 2016. Carbon nanotubes growth on expanded perlite particles via CVD method: The influence of the substrate morphology. Chemical Engineering Journal. doi: http:// dx.doi.org/10.1016/j.cej.2016.01.112.
18. Reis, J.M.L. 2010. Fracture assessment of polymer concrete in chemical degradation solutions. Construction and Building Materials. 24, 1708.

19. Reis, J.M.L. and Jurumenha, M.A.G. 2013. Investigation on the effects of polymer impregnated aggregate on polymer mortars properties. Materials and Structures, 46, 1383.

20. Sengula, O., Azizib, S., Karaosmanoglub, F., and Tasdemira, M.A. 2011. Effect of expanded perlite on the mechanical properties and thermal conductivity of lightweight concrete. Energy and Buildings, 43, 671 .

21. Silva, L.M., Ribeiro, R.A., Labrincha, J.A., and Ferreira, V.M. 2010. Role of lightweight fillers on the properties of a mixed-binder mortar. Cement \& Concrete Composites, 32, 19.

22. Topçu, İ.B., and Işıkdağ, B. 2008. Effect of expanded perlite aggregate on the properties of lightweight concrete. Journal of Materials Processing Technology, 204, 34. 